\title{
Associação das medidas de desempenho para pagamento de bônus aos executivos com dependência de capital humano
}

\section{Association of performance measures for payment of bonuses to executives with dependence of human capital}

Asociación entre medidas de desempeño para pago de bonus a los ejecutivos y la dependencia de capital humano

\section{Ilse Maria Beuren}

Doutora em Controladoria e Contabilidade pela FEA/USP

Professora do Programa de Pós-Graduação em Ciências Contábeis da

Universidade Federal do Paraná

Endereço: Av. Prefeito Lothário Meissner, $\mathrm{n}^{\circ}$ 632, Campus III, Jardim Botânico

CEP: 80210-070 - Curitiba/PR - Brasil

E-mail: ilse.beuren@gmail.com

Telefone: (41) 3360-4193

\section{Itzhak David Simão Kaveski}

Mestre em Ciências Contábeis pela Universidade Regional de Blumenau

Professor de Graduação em Ciências Contábeis da Universidade Federal de Mato Grosso do

Sul

Endereço: Avenida Rio Branco, $\mathrm{n}^{\circ}$ 1.270, Sala H 221, Bairro Universitário

CEP: 79304-020 - Corumbá/MS - Brasil

E-mail: itzhak.kaveski@ufms.br

Telefone: (67) 3234-6861

\section{Vitor Paulo Rigo}

Mestre em Ciências Contábeis pela Universidade Regional de Blumenau

Endereço: Rua Maria Paese, $\mathrm{n}^{\circ}$ 10, Bairro Universitário

CEP: 89560-000 - Videira/SC - Brasil

E-mail: vprigo@gmail.com

Telefone: (49) 3566-7120

Artigo recebido em 03/04/2013. Revisado por pares em 08/11/2013. Reformulado em 07/12/2013. Recomendado para publicação em 03/02/2014 por Sandra Rolim Ensslin (Editora Científica). Publicado em 08/04/2014. 


\title{
Resumo
}

O estudo objetiva verificar a associação das medidas de desempenho utilizadas no pagamento de bônus aos executivos com a dependência de capital humano e o efeito moderador da estrutura de remuneração em empresas listadas na BM\&FBovespa. Os resultados apontam que dependência de capital humano está negativamente relacionada com uso de medidas de recursos humanos no pagamento de bônus aos executivos. Conclui-se que o uso de medidas não financeiras e de recursos humanos para pagamento de bônus aos executivos nas empresas dependentes de capital humano é maior quando adotam estruturas de remuneração igualitária, do que com estruturas de remuneração hierárquica.

Palavras-chave: Capital humano. Estrutura de remuneração. Pagamento de bônus.

\begin{abstract}
The goal of this study is to investigate the association of performance measures used to pay bonuses to executives with the dependence of human capital and the moderating effect of the compensation structure in companies listed on BM\&FBovespa. The results indicate that reliance on human capital is negatively related to the use of human resources measures for the payment of bonuses to executives. It is concluded that the use of non-financial measures and human resources for the payment of bonuses to executives in companies dependent on human capital is greater when they adopt egalitarian compensation structures, than with hierarchical compensation structures.
\end{abstract}

Keywords: Human capital. Compensation structure. Payment of bonuses.

\section{Resumen}

El estudio pretende verificar la asociación entre las medidas de desempeño utilizadas en el pago de bonus a los ejecutivos con dependencia de capital humano y el efecto moderador de la estructura de remuneración en empresas listadas en BM\&FBovespa. Los resultados indican que la dependencia de capital humano está negativamente relacionada con el uso de medidas de recursos humanos en el pago de bonus a los ejecutivos. Se concluye que el uso de medidas no financieras y de recursos humanos para el pago de bonus a los ejecutivos en las empresas dependientes de capital humano es más alto cuando se adoptan estructuras de remuneración igualitaria que cuando se adoptan estructuras de remuneración jerárquica.

Palabras clave: Capital humano. Estructura de remuneración. Pago de bonus. 


\section{Introdução}

A remuneração recebida pelo trabalho assalariado normalmente é a única fonte de recursos financeiros para a maioria das pessoas. Essa dependência torna o salário fundamental para garantir sua sobrevivência. Por outro lado, os empregadores necessitam diariamente reduzir custos e garantir produtividade e qualidade dos produtos e serviços das empresas. Por isso, a busca de um modelo equilibrado de remuneração que satisfaça os referidos interesses conflitantes entre ambas as partes é um dos principais desafios das organizações (GERHART; MINKOFF; OLSEN, 1995).

Essa preocupação pode ser percebida em estudos como o de Oyadomari et al. (2009), que investigou se há congruência entre as práticas de remuneração variáveis adotadas pelas empresas e as metas do sistema de controle gerencial. Defende-se a importância do alinhamento das medidas de desempenho utilizadas na remuneração dos executivos e os objetivos organizacionais, com o propósito de minimizar os possíveis conflitos de agência. Essa situação pode ser materializada em contratos de remuneração que estabelecem o alcance de metas e um desempenho individual que se reflita em ganhos globais para o negócio (BALSAM; FERNANDO; TRIPATHY, 2011).

Nesta perspectiva identificaram-se alguns estudos anteriores que pesquisaram a influencia dos incentivos financeiros no desempenho organizacional (BANKER; LEE; POTTER, 1996; KRAUTER, 2009; LARRATE; OLIVEIRA; CARDOSO, 2011). O uso de medidas financeiras para basear o pagamento de bônus aos executivos de topo é prática comum nas organizações (MCKENZIE; SHILLING, 1998). Estes autores apontam para a existência de diferentes estruturas e políticas de remuneração, e as classificam em igualitárias e hierárquicas. As estruturas de remuneração hierárquicas possuem como principal característica, alta diferença de valores financeiros entre os executivos de topo e os funcionários da base, enquanto, nas estruturas igualitárias essas diferenças são consideravelmente inferiores (COWHERD; LEVINE, 1992).

$\mathrm{O}$ pagamento de bônus baseados em indicadores financeiros tende a promover o comportamento de curto prazo por parte dos executivos, cuja preocupação remete-se aos resultados trimestrais. Em uma possível decisão de investimento em capital humano, a pressão dos indicadores financeiros pode promover o corte de treinamentos e capacitação, prejudicando os resultados de longo prazo da organização (LAVERTY, 1996; LAU, 2011). Além dos prováveis comportamentos de curto prazo expostos, Dalmacio, Rezende e Slomski (2009) alertam para a necessidade de uma análise setorial quando da definição dos indicadores contábeis que irão parametrizar a remuneração variável. Advertem que determinados índices podem ser obtidos em função da atividade econômica e não do desempenho do gestor, o que macula o propósito de medição do desempenho individual.

No Brasil, os modelos de remuneração variáveis mais utilizados são: bônus, comissões, incentivos, participação nos resultados (gainsharing), participação nos lucros (profitsharing) e participação acionária (XAVIER; SILVA; NAKAHARA, 1999). Corroborando, Larrate, Oliveira e Cardoso (2011) analisaram 142 companhias brasileiras e constataram que a maioria adota alguma forma de remuneração variável aos seus gestores. $\mathrm{O}$ estudo demonstrou também que duas em cada três empresas que possuem planos de longo prazo utilizam opções de ações como parte do plano.

Lau (2011) analisou separadamente os efeitos das medidas não financeiras e financeiras em uma amostra de 121 gestores, com o objetivo de compreender a efetiva

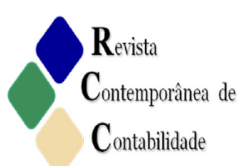


necessidade de estabelecer os dois modelos de forma a se complementarem e testou a sua ação individualizada. Os achados sugerem maior eficiência dos indicadores não financeiros no que diz respeito à capacidade de influenciar o desempenho dos colaboradores. A preocupação em buscar alternativas de medidas não financeiras para pagamento de bônus é ainda maior nas organizações intensivas em capital humano. Lev (2001) afirma que nas regras tradicionais de contabilidade, investimento em treinamento é mensurado como despesa do exercício. Assim, se as metas forem estabelecidas exclusivamente por indicadores financeiros pode influenciar a decisão do gestor na redução de recursos para tal atividade.

Neste sentido, Hajiha e Hasanloo (2012) analisaram os efeitos do capital humano sobre a rentabilidade e o valor de mercado de 60 empresas iranianas de oito setores industriais listados na Bolsa de Valores do Teerã, considerando o período de 2005 a 2009. Os resultados apresentaram que há relação significante entre o valor do capital humano e o valor de mercado das empresas. Quanto a rentabilidade, os achados não demonstraram correlação significante com o valor do capital humano das empresas. Em outras palavras, embora não tenham observado efeitos do capital humano na rentabilidade das empresas iranianas pesquisadas, o mercado considera o valor desse ativo.

Widener (2006) selecionou uma amostra de 117 empresas listadas na Bolsa de Valores dos Estados Unidos e examinou a associação do bônus concedido aos executivos com a dependência de capital humano. Como diferencial, analisou se o capital humano afeta a estrutura de remuneração do bônus aos executivos e se este bônus é concedido com o uso de medidas financeiras e não financeiras. Encontrou evidências nestas empresas de que o uso de mão de obra intensiva resulta em maior probabilidade de enfatizar medidas não financeiras, junto com as tradicionais medidas financeiras, no pagamento de bônus aos executivos.

Neste estudo replica-se a pesquisa de Widener (2006), tendo como questão norteadora a seguinte pergunta de pesquisa: A dependência de capital humano e a estrutura de remuneração das empresas estão associadas com o uso de medidas não financeiras no pagamento de bônus aos executivos? Deste modo, o estudo objetiva verificar a associação das medidas de desempenho utilizadas no pagamento de bônus aos executivos com a dependência de capital humano e o efeito moderador da estrutura de remuneração em empresas listadas na BM\&FBovespa. Como se replica o estudo de Widener (2006) em empresas brasileiras, apresenta-se ao final do estudo um comparativo dos resultados de ambas as pesquisas.

A justificativa apresentada por Widener (2006) para o estudo é que o capital humano é cada vez mais importante para as organizações no ambiente moderno. No entanto, aponta para a escassez no debate em relação à estrutura de remuneração dos executivos nas empresas. Assim, a contribuição do estudo está em verificar o uso de medidas financeiras e não financeiras de desempenho e a influência do capital humano no pagamento de bônus aos executivos em empresas brasileiras, um ambiente em que a estrutura de remuneração dos executivos ainda é pouco investigada. A justificativa da escassez no debate em relação à estrutura de remuneração dos executivos se aplica no contexto brasileiro devido a ausência de informações para pesquisas, alterado com normativa recente a respeito da obrigatoriedade de sua transparência e evidenciação ao público, conforme Instrução CVM no 480/09.

Este estudo centra-se nas medidas de desempenho utilizadas na remuneração de executivos por meio de opções de ações, as stock opitions. Tal abordagem diferencia o estudo e revela sua importância por se tratar de uma forma de remuneração que, embora apresente crescimento no Brasil nos últimos anos, ainda pode conquistar maior espaço entre as empresas. A relevância do estudo está em considerar que o pagamento de bônus sob a forma

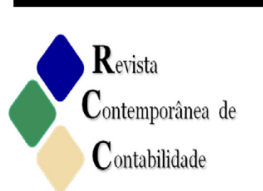

ISSN 2175-8069, UFSC, Florianópolis, v. 11, n. 22, p. 03-24, jan./abr. 2014 
de remuneração variável para executivos tem como prática comum basear-se em indicadores financeiros, contudo esta base tem sido criticada por falta de relevância na atual economia, sugerindo que se baseie também em medidas não financeiras.

O estudo também se diferencia do realizado por Hajiha e Hasanloo (2012) em empresas iranianas, que utilizou a remuneração de bônus sob a forma monetária, além de tê-la utilizado como variável independente juntamente com o capital humano, e como variáveis dependentes a rentabilidade e o valor de mercado das empresas. Já neste estudo, assim como no de Widener (2006), analisou-se a relação do capital humano com medidas de desempenho para pagamento de bônus a partir de variáveis dummy como dependentes e o capital humano como independente. O propósito é verificar se o capital humano interfere nas medidas de desempenho para pagamento de bônus. E não se o capital humano interfere no valor da remuneração dos executivos, conforme considerado por aqueles autores.

\section{Fundamentação Teórica}

\subsection{Capital Humano}

O termo capital humano, segundo Crawford (1994), foi utilizado na literatura econômica pela primeira vez no estudo de Schultz (1961). Os avanços nos estudos relacionados ao tema denotam sob diferentes perspectivas a relevância do capital humano nas organizações contemporâneas. A importância do capital humano é percebida na sua capacidade criativa e de inovação nas organizações, bem como os conhecimentos, habilidades e experiências individuais dos colaboradores (EDVINSSON; MALONE, 1998). Como exemplos de capital humano, Stewart (1998) aponta, entre outros, a capacidade intelectual, competência e clima organizacional agradável. O autor também delega à qualidade do capital humano a capacidade da empresa em gerar inovação em seus processos e produtos.

No entanto, um dos dilemas enfrentados pelas organizações é encontrar maneiras de gerenciar os aspectos relacionados ao capital humano. Desde criar métodos de retenção e disseminação dos conhecimentos gerados, até estabelecer indicadores capazes de medir a eficiência e o efetivo impacto gerado nos resultados financeiros. Esse aspecto é destacado por Grant (1991) ao apontar para a problemática de que no sentido do controle, a força de trabalho é móvel e não pertence à empresa, logo o capital humano pode abandonar a empresa. Por isso, o autor destaca a necessidade de criar mecanismos para extrair o conhecimento que está incorporado em seus empregados por meio da formação de um ambiente colaborativo.

Schulz (2001) concorda com esse pensamento e reconhece que o conhecimento é mais eficaz quando trocado com outras pessoas. Alerta para o fato de quanto maior a dependência das empresas em capital humano, maior devem ser os esforços de cooperação, intercâmbio de conhecimentos e colaboração entre os empregados. Esse ambiente é difícil de gerenciar, pois a ligação entre o emprego de capital humano e os resultados não são completamente evidentes. Wang e Shieh (2008) investigaram a correlação entre investimento em capital humano e desempenho organizacional, mediram ainda a cultura organizacional e o desempenho e, finalmente, o efeito da cultura organizacional sobre a correlação entre os investimentos em capital humano e o desempenho das organizações.

O investimento na absorção, estímulo e manutenção do capital humano podem melhorar as competências dos membros das organizações e melhorar seus relacionamentos

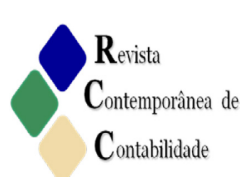


interpessoais. Recomenda-se que as empresas adotem uma estratégia adequada à sua própria situação. A interação entre o desempenho organizacional e o investimento em capital humano, mostrou-se viável, e a possibilidade de maior taxa de retorno sobre o investimento mostra-se possível (WANG; SHIEH, 2008). Neste contexto de desempenho, o capital humano centra-se no valor que é adicionado ao negócio de uma organização. As empresas detentoras de capital humano capacitado são suscetíveis a ter desempenho superior no mercado em que atuam. $\mathrm{O}$ capital humano aumenta na medida em que se acumula pessoal especializado e quando se incentiva a disseminação do conhecimento para toda a organização (HSU; WANG, 2012).

Entende-se que a intensidade elevada da dependência de capital humano por parte das empresas necessita ser acompanhada pela preocupação em desenvolver medidas capazes de apontar a importância dos colaboradores em seus processos, de modo que o valor agregado por eles seja facilmente visível pelos tomadores de decisões estratégicas na empresa. A importância de medir a força de trabalho das empresas é reconhecida, porém, as diferentes demandas por informações entre executivos e investidores podem inviabilizar algumas empresas a dedicar o esforço necessário em tal certame. Ao contrário, em alguns casos o pessoal é o primeiro a ser eliminado quando uma empresa decide reduzir e cortar custos. Propõem-se medidas mais abrangentes do capital humano, com a integração de medidas tradicionais de capital humano e informações adicionais (por exemplo, nível de escolaridade, experiência e motivação), de modo a tornar as informações atraentes aos diferentes usuários (LIM; CHAN; DALLIMORE, 2010).

Neste sentido, Lev (2001) alerta sobre a importância do uso de indicadores intangíveis e de características não financeiras. Para exemplificar, o autor cita o investimento realizado em formação do capital humano. Enquanto o treinamento é importante para o desempenho de longo prazo da empresa, as medidas financeiras de curto prazo mostram resultados reduzidos devido à contabilização da formação de pessoal como custo no resultado do exercício. Neste contexto, chama-se a atenção para o efeito nocivo do uso exclusivo de medidas financeiras tradicionais, como o lucro por ação. Destaca-se a importância do uso de medidas não financeiras para medir o desempenho do capital humano, nos planos de pagamentos de bônus por desempenho dos executivos de topo (KAPLAN; NORTON, 1996).

\subsection{O Efeito Moderador da Estrutura de Remuneração}

A remuneração pode ser considerada uma das principais, e para muitos a principal variável na relação de trabalho entre empregador e empregado. No caso dos funcionários, estes normalmente dependem exclusivamente dos salários e benefícios recebidos para garantir sua sobrevivência. No outro extremo, os empregadores convivem com a pressão de redução contínua de custos, aumento de produtividade e qualidade. Diante disso, a capacidade de gerir a política de remuneração é fundamental (GERHART; MINKOFF; OLSEN, 1995).

A política de remuneração estabelecida é capaz de influenciar no desempenho organizacional como um todo, o que justifica o estabelecimento de modelos alternativos. A remuneração variável é defendida como uma das alternativas para incentivar o desempenho das pessoas nas funções que ocupam na empresa. Uma das principais formas de incentivo são os pagamentos de bônus para metas de curto prazo e as opções de ações utilizadas para promover comportamentos de longo prazo (LARRATE; OLIVEIRA; CARDOSO, 2011).

Dentre as alternativas de remuneração variável, as mais utilizadas no Brasil, conforme Xavier, Silva e Nakahara (1999), são:

\footnotetext{
$\left\{\begin{array}{l}\boldsymbol{R}_{\text {evista }} \\ \mathbf{C}_{\text {ontemporânea de }} \\ \text { Contabilidade }\end{array}\right.$
}

ISSN 2175-8069, UFSC, Florianópolis, v. 11, n. 22, p. 03-24, jan./abr. 2014 
a) gratificação - utilizado normalmente para remunerar os altos escalões das companhias, o valores são pagos em conformidade com o resultado obtido;

b) comissão - trata-se de uma das formas mais antigas para remunerar os funcionários da área comercial, é um modelo bastante utilizado ao aplicar um percentual sobre as vendas de determinado período;

c) incentivos/campanhas - visa estimular o alcance de metas pré-estabelecidas dentro de um período de tempo determinado. Na maioria dos casos o pagamento é feito por meio de bens ou viagens;

d) participação nos resultados (gainsharing) - remuneração realizada em detrimento da redução de custos ou aumento de produtividade almejada, ou ainda, diferentes metas que por ventura sejam determinadas;

e) participação nos lucros (profitsharing) - são estabelecidos critérios, os quais servem de base para a distribuição de resultados aos empregados; e

f) participação acionária - é reconhecida como uma forma de incentivo de longo prazo, normalmente destinada aos cargos de direção de empresas de capital aberto. Trata-se da distribuição ou venda facilitada de ações, que podem ser negociadas posteriormente.

Widener (2006) cita a Teoria da Equidade para explicar que as pessoas fazem comparações entre a remuneração que recebem e a remuneração recebida pelos outros. $\mathrm{O}$ autor ainda destaca os resultados negativos advindos deste comportamento, como o sentimento de desigualdade e o consequente reflexo na baixa produtividade dos colaboradores. Cowherd e Levine (1992) alertam que os funcionários remunerados em uma estrutura hierárquica tendem a sentirem-se injustiçados, o que afeta negativamente o comportamento em relação aos objetivos organizacionais. Em contraste, estruturas igualitárias proporcionam um ambiente de maior coesão entre os funcionários, o que leva a um maior compromisso em relação às metas organizacionais e aumento da qualidade do produto.

Os efeitos negativos podem tornar a tarefa das empresas de extrair benefícios do seu capital humano mais difícil. Por isso, as organizações que possuem maior grau de dependência de capital humano, terão maior necessidade de informações não financeiras, especialmente medidas de recursos humanos, de modo a superar os efeitos comportamentais produzidos pela estrutura de remuneração (WIDENER, 2006). Para o autor, a necessidade de obtenção de informações em medidas não financeiras será menor nas empresas que contam com o capital humano em um ambiente igualitário, ao contrário daquelas com ambiente hierárquico. Defende ainda que a estrutura de remuneração é a moderadora na relação entre a dependência de capital humano e a necessidade de utilização de medidas não financeiras.

A discussão pode ser ampliada para a definição de indicadores de desempenho que possam servir de base para remunerar os funcionários. A remuneração baseada no desempenho pode ser uma dentre várias alternativas para garantir a obtenção de vantagem competitiva sustentável e alinhar os interesses de gestores e investidores, colaborando para suavizar os conflitos oferecidos em sistemas hierárquicos de remuneração. Entretanto, admitem-se dificuldades em estabelecer indicadores de desempenho capazes de promover o alinhamento de interesse sugerido e a neutralização dos efeitos da estrutura de remuneração.

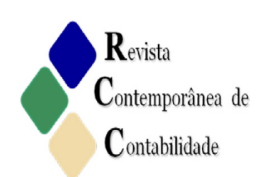




\subsection{Medidas de Desempenho no Pagamento de Bônus}

As discussões relacionadas aos planos de pagamentos de bônus aos executivos oferecem um cenário interessante por dois motivos em especial. Primeiramente, é uma sistemática cada vez mais utilizada na remuneração total dos executivos. Em segundo lugar, é a parte da remuneração de executivos que se destina a motivar comportamentos gerenciais (BALKCOM; ITTNER; LARCKER, 1997). É prática comum nas organizações estabelecer contratos de pagamentos de bônus aos executivos de topo, com indicadores baseados na contabilidade financeira, em que se destacam o lucro líquido, lucro por ação e retorno sobre ativos (MCKENZIE; SHILLING, 1998). No entanto, uma visão merecedora de análise é a possibilidade de medidas exclusivamente financeiras incentivarem um foco de curto prazo nas decisões dos executivos (LAVERTY, 1996).

Kaplan e Norton (1996) salientam que o uso de medidas não financeiras pode equilibrar as distorções promovidas pelos indicadores financeiros de curto prazo, e incentivar comportamentos que privilegiem decisões que levam em consideração os resultados de longo prazo. Ittner, Larcker e Rajan (1997) acrescentam que a maioria das empresas utiliza planos de curto prazo, especialmente anuais, em seus programas de remuneração. Os autores defendem ainda que as medidas de desempenho utilizadas nos contratos de compensação devem estar ligadas à estratégia da organização, e incentivam o estudo de indicadores não financeiros para estabelecer esta situação.

Balsam, Fernando e Tripathy (2011) reforçam a importância da ligação entre a estratégia da empresa e a política de pagamentos de bônus. Os autores destacam os achados de Balkin e Comez-Mejia (1990), que demonstram a relação da compensação com a estratégia corporativa. Também citam a pesquisa de Montemayor (1996), que relata que o desempenho inferior da organização está ligado à falta de congruência entre a política de remuneração e a estratégia dos negócios. Um exemplo da ligação entre remuneração e estratégia é quando a empresa decide intensificar a política de inovação e desenvolvimento de novos produtos e estabelece como indicador principal de remuneração variável dos executivos o número de patentes licenciadas (BALKIN; MARKMAN; GOMEZ-MEJIA, 2000).

Oyadomari et al. (2009) afirmam que a falta de congruência entre as metas pessoais e organizacionais é capaz de provocar o efeito inverso daquele estabelecido quando adotada a política de remuneração, que é fazer com que as pessoas gerem valor para o negócio. Com o objetivo de minimizar esses conflitos, o sistema de remuneração variável apresenta-se como uma das alternativas ante o sistema tradicional, no qual o salário fixo é a base dos pagamentos. O nível de contribuição do colaborador à organização passa a ser a base para a remuneração, tornando mais perceptível o desempenho individual e os resultados produzidos no todo (OYADOMARI et al., 2009).

Ittner, Larcker e Rajan (1997) argumentam ainda que as medidas financeiras tradicionais podem ser apropriadas para a realidade de empresas com foco na minimização de custos e resultados de curto prazo. No entanto, nas organizações com estratégia voltada à inovação, medidas não financeiras podem contribuir mais para a estratégia estabelecida. As medidas não financeiras usam expressões não monetárias, tornando-as transmissoras dos objetivos organizacionais junto aos colaboradores. A liberdade da expressão monetária permite que as medidas sejam materializadas nas mais diferentes formas, possibilitando uma variedade maior de medidas. Por exemplo, para análise dos clientes, pode-se utilizar a taxa de satisfação, taxas de retenção, número de reclamações, número de novos clientes, entre outras

\footnotetext{
$\left\{\begin{array}{l}\mathbf{R}_{\text {evista }} \\ \mathbf{C}_{\text {ontemporânea de }} \\ \text { Contabilidade }\end{array}\right.$
}

ISSN 2175-8069, UFSC, Florianópolis, v. 11, n. 22, p. 03-24, jan./abr. 2014 
que se julgue necessária (LAU, 2011).

Outro enfoque atribuído é a avaliação individual como parte do conjunto de medidas de desempenho, na qual pode ser baseado o pagamento de bônus aos executivos. Essa abordagem é reconhecida pela dificuldade em estabelecer critérios de desempenhos específicos, e a sua exposição à necessidade de julgamentos também é fator de preocupação, porém, apresenta-se como uma proposta diferenciada em relação às medidas contábeis tradicionais (BUSHMAN; INDJEJIKIAN; SMITH, 1996).

De modo geral, medidas financeiras são necessárias, mas não suficientes, o segmento de atuação da empresa pode contribuir para mais ou para menos em relação à necessidade do uso de medidas não financeiras para remunerar o desempenho. As medidas financeiras refletem os acontecimentos do passado, o que não significa que são menos importantes, mas as empresas necessitam de indicadores não financeiros capazes de indicar o desempenho futuro (KAPLAN; NORTON, 1996).

A revisão teórica apresentada teve o intuito de expor o debate inerente à relevância do capital humano nas organizações, o efeito moderador atribuído a estrutura de remuneração e as possibilidades advindas do processo de construção da mesma, bem como a discussão relacionada aos indicadores utilizados no pagamento de bônus. Para este estudo, esclarece-se que os bônus investigados são aqueles pagos por meio de opções de ações ou stock options, por se tratar, de acordo com a literatura, de um mecanismo que privilegia o longo prazo.

\subsection{Estudo de Widener (2006)}

A pesquisa de Widener (2006), realizada nos Estados Unidos, é relatada em separado por ser a referência do presente estudo. Publicada no periódico Management Accounting Research, sob o título Human capital, pay structure, and the use of performance measures in bonus compensation, investiga a associação do uso de medidas de desempenho com a dependência de capital humano. $\mathrm{O}$ autor aponta que o principal problema nas empresas não é com o reflexo no curto prazo dos investimentos sobre os resultados trimestrais, mas com o desejo dos gestores alcançar os objetivos de curto prazo por causa do seu impacto na remuneração dos executivos.

Executivos focados em números financeiros trimestrais possuem um incentivo para abandonar o trabalho que implica investimentos, a fim de melhorar os resultados financeiros trimestrais, embora o desinvestimento possa ser prejudicial à saúde da organização no longo prazo. A partir deste debate, Widener (2006) apresenta o objetivo de seu estudo, que é fornecer evidências sobre o debate por meio da análise do uso de medidas de desempenho no pagamento de bônus para executivos. $\mathrm{O}$ autor busca averiguar se as empresas que dependem do seu trabalho para sustentar suas operações complementam as tradicionais medidas financeiras com medidas não financeiras.

Para operacionalizar o objetivo do estudo levantou quatro hipóteses. Na elaboração das duas primeiras hipóteses considerou quatro aspectos. Em primeiro lugar, que há elos fracos entre esforço e resultados em empresas de trabalho intensivo. Em segundo lugar, devido as preocupações de risco moral, informações apropriadas devem ser recolhidas e monitoradas. Em terceiro lugar, as medidas financeiras são medidas incompletas e que não captam plenamente os objetivos relacionados com a dependência de capital humano. Em quarto lugar, para empresas de trabalho intensivo, medidas não financeiras prestam informação incremental ao contido em medidas financeiras e, assim, ajudam a reduzir os

11 ISSN 2175-8069, UFSC, Florianópolis, v. 11, n. 22, p. 03-24, jan./abr. 2014 Rerista Contemporânea de Contabilidade 
custos de agência. Partindo destas suposições elaborou o primeiro conjunto de hipóteses:

$\mathrm{H}_{1 \mathrm{a}}$ : A probabilidade do uso de informações não financeiras no pagamento de bônus aumenta com a dependência de capital humano.

$\mathrm{H}_{1 \mathrm{~b}}$ : A probabilidade do uso de medidas de recursos humanos no pagamento de bônus aumenta com a dependência de capital humano.

Para a elaboração das outras duas hipóteses fez várias considerações. Para que uma empresa possa extrair benefícios de seu capital humano, deve haver esforços de cooperação, troca de conhecimento e colaboração entre trabalhadores e um ambiente de compartilhamento coletivo. Ambientes de pagamento hierárquicos são caracterizados por falta de coerência objetiva, sentimentos de injustiça e insatisfação. Estes efeitos negativos irão agravar problemas de risco moral, tornando difícil a extração dos benefícios do capital humano.

As empresas que dependem de capital humano vão contar isso com o uso de informações não financeiras e com medidas de recursos humanos, especialmente, quando há uma estrutura de remuneração hierárquica, a fim de tentar superar os efeitos negativos de comportamentos produzidos pela estrutura de remuneração hierárquica. Em contraste, um ambiente de pagamento igualitário é caracterizado por maior compromisso com as metas organizacionais. Isto contribuirá para reduzir a quantidade de riscos morais presentes na empresa e a possibilidade de uma empresa extrair melhor os benefícios de seu capital humano. Desse modo, a necessidade de informação adicional baseada em medidas não financeiras não será tão grande para empresas que dependem de capital humano em um ambiente igualitário em oposição a um ambiente hierárquico.

Em síntese, argumenta-se que a estrutura de remuneração vai moderar a relação entre a dependência de capital humano e a utilização de medidas não financeiras. Isso leva às seguintes hipóteses:

$\mathrm{H}_{2 \mathrm{a}}$ : A estrutura de remuneração modera a relação entre a utilização de medidas não financeiras e a dependência de capital humano.

A probabilidade da utilização de medidas não financeiras no pagamento de bônus nas empresas com dependência de capital humano é maior quando usam estruturas de remuneração hierárquica do que quando usam estruturas de remuneração igualitária.

$\mathrm{H}_{2 b}$ : A estrutura de remuneração modera a relação entre a utilização de medidas de recursos humanos e a dependência de capital humano.

A probabilidade da utilização de medidas de recursos humanos no pagamento de bônus nas empresas com dependência de capital humano é maior quando usam estruturas de remuneração hierárquica do que quando usam estruturas de remuneração igualitária.

Os dados foram coletados nas demonstrações contábeis publicadas de 177 empresas, classificando-as quanto as medidas adotadas para pagamento de bônus em duas categorias: (i) empresas que enfatizam medidas financeiras; (ii) empresas que utilizam medidas financeiras e não financeiras. Utilizando procedimentos estatísticos, o autor encontrou evidências de que o uso de mão de obra intensiva em empresas possui uma maior probabilidade de colocar ênfase em medidas não financeiras, junto com as tradicionais medidas financeiras, e uma menor probabilidade de depender exclusivamente de medidas financeiras. Igualmente, esta relação é administrada pela estrutura de remuneração da empresa.

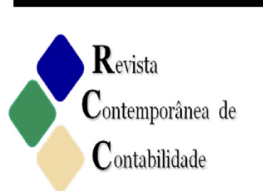

ISSN 2175-8069, UFSC, Florianópolis, v. 11, n. 22, p. 03-24, jan./abr. 2014 


\section{Metodologia}

Esta pesquisa caracteriza-se como descritiva, por focalizar a descrição da relação entre variáveis. O procedimento para a coleta dos dados consistiu de pesquisa documental, pois se utilizou das Demonstrações Financeiras, relativas ao ano de 2011, e do Formulário de Referência da BM\&FBovespa como fonte dos dados. E a abordagem da pesquisa é quantitativa, devido ao emprego de técnicas estatísticas para obter e analisar os resultados.

\subsection{População e Amostra}

Como este estudo replica a pesquisa de Widener (2006) em empresas brasileiras, a população desta pesquisa é composta pelas companhias abertas listadas na BM\&FBovespa, exceto as classificadas no setor econômico "Financeiro e Outros", devido às características singulares de suas atividades. Para a amostra da pesquisa foram selecionadas apenas as companhias que realizaram pagamento de bônus com base em ações.

Optou-se por analisar empresas com sistema de pagamento de bônus com base em ações, visto que o estudo de Widener (2006) também adotou este critério, favorecendo assim a análise comparativa. A Tabela 1 demonstra o número de companhias pertencentes à amostra da pesquisa, bem como o setor econômico em que estão listadas na BM\&FBovespa.

Tabela 1 - População e amostra da pesquisa

\begin{tabular}{l|c|c|c|c}
\hline \multicolumn{1}{c|}{ Setor econômico da BM\&FBovespa } & População & \% da População & Amostra & \% da Amostra \\
\hline Bens Industriais & 36 & $9,89 \%$ & 3 & $5,00 \%$ \\
Construção e Transporte & 66 & $18,13 \%$ & 16 & $26,67 \%$ \\
Consumo Cíclico & 74 & $20,33 \%$ & 14 & $23,33 \%$ \\
Consumo Não Cíclico & 49 & $13,46 \%$ & 11 & $18,33 \%$ \\
Materiais Básicos & 41 & $11,26 \%$ & 4 & $6,67 \%$ \\
Petróleo, Gás e Biocombustíveis & 7 & $1,92 \%$ & 4 & $6,67 \%$ \\
Tecnologia da Informação & 8 & $2,20 \%$ & 1 & $1,67 \%$ \\
Telecomunicações & 10 & $2,75 \%$ & 1 & $1,67 \%$ \\
Utilidade Pública & 73 & $20,05 \%$ & 6 & $10,00 \%$ \\
\hline \multicolumn{1}{c|}{ Total } & $\mathbf{3 6 4}$ & $\mathbf{1 0 0 , 0 0 \%}$ & $\mathbf{6 0}$ & $\mathbf{1 0 0 , 0 0 \%}$ \\
\hline \multicolumn{2}{c}{}
\end{tabular}

Fonte: Dados da pesquisa.

Inicialmente a amostra da pesquisa era composta de 73 empresas. Contudo, resultou em 60 empresas porque não foi possível obter de algumas delas todos os dados. Foram excluídas da amostra as que não divulgaram o número de funcionários e o valor de mercado.

\subsection{Coleta e Análise dos Dados}

Os dados utilizados para a análise estatística foram retirados das Demonstrações Financeiras das empresas e do Formulário de Referência de 2011. Foram considerados os mesmos dados utilizados no estudo de Widener (2006), apresentados no Quadro 1.

A remuneração dos administradores começou a ser evidenciada no Brasil a partir da determinação da Instrução Normativa $n^{\circ} 480$ da Comissão de Valores Mobiliários (CVM), de 7 de dezembro de 2009, por meio do Formulário de Referência, com a segregação da remuneração em: fixa, variável, benefícios pós-emprego, benefícios motivados pela cessação do exercício do cargo e o bônus baseado em ações. Esta Instrução Normativa entrou em vigor 
em $1^{\circ}$ de janeiro de 2010, sobre as informações relativas aos três últimos exercícios sociais e do exercício corrente, ou seja, obrigou as empresas retroagir a evidenciação para os anos de 2007, 2008 e 2009, além da publicação da remuneração dos administradores no ano de 2010.

Quadro 1 - Variáveis utilizadas no estudo base

\begin{tabular}{|c|c|c|}
\hline Dados & Variável & Fórmula \\
\hline \multirow{4}{*}{ Dependentes } & \multirow{4}{*}{ FOURCAT } & Proxy 1 = $\mathrm{O}$ bônus é concedido apenas com base em medidas financeiras. \\
\hline & & $\begin{array}{l}\text { Proxy } 2 \text { = O bônus é concedido com base em medidas financeiras e não } \\
\text { financeiras, mas um limite baseado em uma medida financeira deve ser } \\
\text { atendido antes que as medidas restantes sejam consideradas. }\end{array}$ \\
\hline & & $\begin{array}{l}\text { Proxy } 3=\text { O bônus é baseado tanto na informação financeira como na não } \\
\text { financeira e não existe um limite que deve ser cumprido em primeiro lugar. }\end{array}$ \\
\hline & & $\begin{array}{l}\text { Proxy } 4 \text { = O bônus é baseado em informações financeiras e não financeiras } \\
\text { e medidas de recursos humanos são especificamente mencionadas. }\end{array}$ \\
\hline \multirow{10}{*}{ Independentes } & \multirow{4}{*}{ HCAP } & $\frac{\text { Proxy } 1+\text { Proxy } 2+\text { Proxy } 3}{3}$ \\
\hline & & Proxy $1=\frac{\text { Custos trabalhistas }}{\text { Despesas com depreciação }}$ \\
\hline & & Proxy $2=\frac{\text { Custos trabalhistas }}{\text { Imobilizado }}$ \\
\hline & & Proxy $3=\frac{\text { Custos trabalhistas }}{\text { Número de empregados }}$ \\
\hline & \multirow[b]{2}{*}{ JÚRIDICA } & Custos trabalhistas/Número de empregados \\
\hline & & $\overline{\text { Remuneração dos executivos/Número de executivos }}$ \\
\hline & TAMANHO & Receita Líquida \\
\hline & \multirow{2}{*}{ CRESCER } & Valor de Mercado \\
\hline & & $\overline{\text { Valor Contábil }}$ \\
\hline & INTERAÇÃO & HCAP x JÚRIDICA \\
\hline
\end{tabular}

Fonte: Adaptado de Widener (2006).

Para identificar nas empresas pertencentes à amostra em que se basearam para o pagamento de bônus em ações, consultou-se o Formulário de Referência disponível no sítio da CVM, no item 13.4, que reporta o plano de remuneração baseado em ações. Para a variável custos trabalhistas, os dados foram retirados da Demonstração do Valor Adicionado das empresas. Já para obter o número de empregados, efetuou-se uma consulta no item 14.1 do Formulário de Referência. Quanto a remuneração dos executivos e o número de executivos, os dados foram retirados do item 13.2 deste mesmo formulário. Os demais dados foram coletados na base de dados Economática.

No que concerne ao significado e operacionalização das variáveis, a seguir apresentase o seu detalhamento. A variável dependente FOURCAT representa os indicadores que as empresas se baseiam para o pagamento de bônus em ações. Todavia, na amostra da pesquisa não se identificaram empresas que se baseiam na Proxy 2.

Nas variáveis independentes, HCAP representa o capital humano das empresas. A proxy JURÍDICA representa a estrutura de remuneração das companhias, em que o valor próximo a 1 indica que a empresa adota estrutura de remuneração igualitária, e o valor

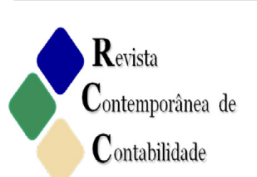


próximo a 0 a estrutura de remuneração hierárquica. O TAMANHO das empresas é obtido a partir da receita líquida. A variável CRESCER, também denominada de market-to-book, de acordo com Ittner, Larcker e Rajan (1997), é uma variável para determinar o crescimento da empresa ou oportunidades de investimento. A proxy INTERAÇÃO realiza a interação entre HCAP e JURIDICA, buscando encontrar relação com vistas ao conjunto de hipóteses $\mathrm{H}_{2}$.

Foram utilizadas as mesmas hipóteses propostas por Widener (2006), já que este estudo buscou replicar a pesquisa do autor no Brasil. Espera-se encontrar resultados semelhantes aos verificados no estudo de referência desta pesquisa. Na análise dos dados, primeiramente utilizou-se da estatística descritiva para a visualização do comportamento dos dados. Em seguida, aplicou-se a correlação de Pearson, que busca uma associação linear entre variáveis. Por fim, aplicou-se a regressão logística binaria e multinominal, para identificar a relação entre a variável dependente e as variáveis independentes. Para os cálculos utilizou-se o software Statistical Package for Social Sciences (SPSS).

A Correlação de Pearson é uma associação linear entre duas variáveis, que varia entre -1 e +1 . O valor próximo de -1 indica que o aumento de uma variável está significativamente associado à diminuição de outra variável. $\mathrm{O}$ valor +1 indica que o aumento de uma variável está significativamente associado ao aumento de outra variável. Se o valor for 0 , indica uma relação não linear entre as variáveis (ANDERSON; SWEENEY; WILLIAMS, 2003).

A Regressão Logística Binaria, segundo Hosmer e Lemeshow (1989), tem como finalidade descrever as relações entre a variável resposta (dependente) e a variável explicativa (independente). A Regressão Logística Multinominal, conforme Fávero et al. (2009, p. 456), "permite que a variável categórica dependente apresente mais de duas categorias, as quais, por sua vez, podem ser de natureza nominal [...] ou ordinal".

\section{Descrição e Análise dos Resultados}

Nesta seção apresentam-se a descrição e a análise dos resultados da pesquisa. Inicia-se pela análise descritiva. Segue-se a análise com a correlação de Pearson. Em seguida apresenta-se a análise multivariada, utilizando a regressão linear binaria e a multivariada. Por fim, faz-se uma comparação dos resultados encontrados com o estudo de Widener (2006).

A Tabela 2 mostra a análise descritiva dos dados, separados de acordo com os indicadores que as empresas se baseiam para o pagamento de bônus em ações, considerando as quatro proxies FOURCAT apresentadas no Quadro 1.

Observa-se na Tabela 2, que o indicador com maior desvio-padrão, isto é, a média das distâncias das observações em relação à média geral da variável para os grupos de empresas, foi o que mede o tamanho da empresa. Este foi encontrado pela receita líquida da que apresentou um desvio-padrão igual 7.571.885,19 (FOURCAT 1), 13.071.425,69 (FOURCAT 2) e 23.058.104,89 (FOURCAT 3). Em contrapartida, o indicador que apresentou menor desvio-padrão nas empresas foi o que mede a jurídica da empresa, isto é, a estrutura de remuneração das empresas. Para este indicador o desvio padrão foi de 0,04 (FOURCAT 1), 0,06 (FOURCAT 2) e 0,09 (FOURCAT 4).

Considerando a média dos indicadores, as empresas que adotam remuneração variável com base em medidas financeiras possuem receita liquida e estrutura de remuneração menor, quando comparadas as empresas que remuneram com base em medidas financeiras e não financeiras e as que utilizam medidas de recursos humanos. Estes resultados corroboram os

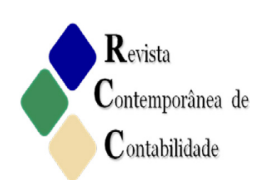


achados do estudo de Widener (2006). Portanto, o tamanho da empresa influencia no tipo de indicador utilizado para o pagamento de bônus em ações.

Tabela 2 - Estatísticas descritivas

\begin{tabular}{c|c|c|c|c|c|c}
\hline Variáveis & FOURCAT & $\mathbf{N}^{\circ}$ & Mínimo & Máximo & Média & Desvio-Padrão \\
\hline \multirow{3}{*}{ CRESCER } & 1 & 26 & 0,17 & 5,38 & 1,41 & 1,39 \\
& 2 & 15 & 0,41 & 3,12 & 1,60 & 0,88 \\
& 4 & 19 & 0,46 & 14,79 & 3,36 & 4,17 \\
\hline \multirow{3}{*}{ HCAP } & 1 & 26 & 4,69 & 70,53 & 20,02 & 14,68 \\
& 2 & 15 & 4,92 & 79,75 & 23,32 & 17,73 \\
& 4 & 19 & 6,09 & 55,84 & 23,51 & 14,89 \\
\hline \multirow{3}{*}{ INTERAÇÃO } & 1 & 26 & 0,06 & 5,45 & 1,23 & 1,29 \\
& 2 & 15 & 0,03 & 19,62 & 2,25 & 4,89 \\
& 4 & 19 & 0,03 & 20,19 & 2,76 & 4,91 \\
\hline \multirow{3}{*}{ JURÍDICA } & 1 & 26 & 0,01 & 0,16 & 0,05 & 0,04 \\
& 2 & 15 & 0,01 & 0,25 & 0,06 & 0,06 \\
& 4 & 19 & 0,00 & 0,38 & 0,08 & 0,09 \\
\hline \multirow{3}{*}{ TAMANHO } & 1 & 26 & $15.649,00$ & $27.126 .719,00$ & $4.621 .093,00$ & $7.571 .885,19$ \\
& 2 & 15 & $9.937,00$ & $46.594 .486,00$ & $7.034 .514,00$ & $13.071 .425,69$ \\
& 4 & 19 & $471.100,00$ & $103.195 .407,00$ & $8.821 .869,95$ & $23.058 .104,89$ \\
\hline
\end{tabular}

Fonte: Dados da pesquisa.

Na Tabela 3 mostra-se a relação entre as variáveis, a partir da aplicação da correlação de Pearson.

Tabela 3 - Correlação das variáveis

\begin{tabular}{c|c|c|c|c}
\hline Variáveis & HCAP & JURÍDICA & TAMANHO & CRESCER \\
\hline FOURCAT & 0,1017 & 0,1411 & 0,1205 & $+0,3062 *$ \\
HCAP & & $+0,6184^{* *}$ & 0,0268 & $-0,0903$ \\
JURÍDICA & & & $-0,1325$ & $-0,0708$ \\
TAMANHO & & & & $-0,0196$ \\
\hline
\end{tabular}

*signif. a $5 \%$; **signif. a $1 \%$.

Fonte: Dados da pesquisa.

Verifica-se na Tabela 3, que a dependência em relação à utilização do capital humano (HCAP) é positiva e significativamente correlacionada com a estrutura de remuneração (JURÍDICA) da empresa $(\mathrm{r}=0,62, \mathrm{p}<0,01)$, ou seja, quanto maior o gasto com capital humano, maior a estrutura de remuneração da empresa. Além disso, o uso de medidas não financeiras (FOURCAT) é marginalmente positivamente correlacionado com a oportunidade de crescimento da empresa $(r=0,31, p<0,05)$, isto é, quanto maior a utilização de medidas não financeiras, maior o crescimento da empresa.

No entanto, não se encontrou correlação entre o capital humano (HCAP) e os indicadores para o pagamento de bônus em ações (FOURCAT) das empresas, uma vez que, os resultados apresentaram significância superior a 0,05 e a 0,01 , respectivamente, o que indica que os coeficientes são todos iguais a zero. Esses resultados contrariam os do estudo de Widener (2006), que identificou correlação positiva entre as variáveis, mas coaduna ao não encontrar correlação entre o crescimento da empresa e os gastos com capital humano.

Ressalta-se que o nível de correlação de $1 \%$ (p-value $<0.01$ ) entre a variável jurídica e capital humano foi idêntico ao estudo de Widener (2006), corroborando assim a suposição de

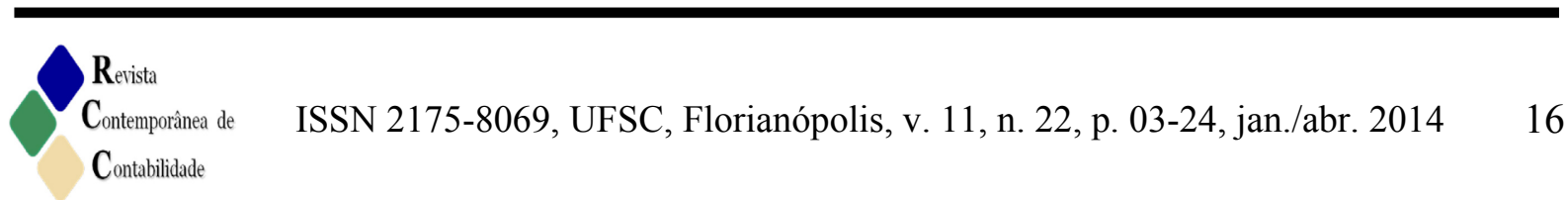


que o fator jurídica (estrutura de remuneração) pode ser um indicativo de que as empresas que adotam uma estrutura de remuneração igualitária investem mais em capital humano.

Para explicar o uso categórico de medidas de desempenho no pagamento de bônus, procedeu-se à análise de regressão logística binaria e multinominal para testar a relação hipotética entre capital humano, estrutura de remuneração, bem como a utilização de medidas de desempenho no pagamento de bônus. Os resultados foram separados em três grupos: Grupo A) a variável dependente assume os valores de duas medidas de desempenho empresas com planos que usam apenas medidas financeiras $(n=26)$, e planos que incluem medidas não financeiras $(\mathrm{n}=34)$; Grupo B) a variável dependente assume os valores das três medidas de desempenho - empresas que utilizam apenas medidas financeiras $(n=26)$, que usam tanto medidas financeiras como não financeiras $(n=15)$, e que usam especificamente medidas de recursos humanos $(\mathrm{n}=19)$; Grupo $\mathrm{C})$ a variável dependente assume os valores de duas medidas de desempenho - empresas que utilizam apenas medidas financeiras $(n=26)$, e as que usam especificamente medidas de recursos humanos $(n=19)$.

Na Tabela 4 mostra-se o resultado da regressão logística binaria do Grupo A.

Tabela 4 - Regressão logística binaria do Grupo A

\begin{tabular}{c|c|c|c|c}
\hline Efeito Omitido & Coeficientes & $\mathbf{- 2 *} \mathbf{L N}(\mathbf{P})$ do MR & Qui-Quadrado & Significativo \\
\hline CONSTANTE & 0,535 & 72,594 & 0,338 & Não \\
TAMANHO & 0,000 & 73,627 & 1,371 & Não \\
JURÍDICA & $-19,995$ & 74,140 & 1,884 & Não \\
HCAP & $-0,052$ & 73,816 & 1,560 & Não \\
INTERAÇÃO & 0,858 & 76,188 & 3,932 & Sim \\
CRESCER & 0,293 & 76,406 & 4,151 & Sim \\
\hline
\end{tabular}

Significativa em $\mathrm{p}<0,10$.

Fonte: Dados da pesquisa.

Nota-se na Tabela 4 que o teste qui-quadrado da interação do capital humano (HCAP) com estrutura de remuneração (JURÍDICA), de 3,932 e p<0,10, é significativa. Assim, rejeitase a hipótese nula, de que os coeficientes são simultaneamente iguais a zero. Como o coeficiente de interação foi positivo, rejeita-se a hipótese $\mathrm{H}_{2 a}$, já que o coeficiente indica que a probabilidade da utilização de medidas não financeiras no pagamento de bônus nas empresas com dependência de capital humano é maior nas com estrutura de remuneração igualitária.

O indicador capital humano (HCAP) não apresentou significância, assim a hipótese nula de que os coeficientes são simultaneamente iguais a zero não é rejeitada. Ao relacionar o indicador de crescimento (CRESCER) com o uso de medidas não financeiras e a dependência de capital humano no pagamento de bônus de executivos, encontra-se resultado positivo e significativo. Depreende-se, assim, que quanto maior é a oportunidade de crescimento da empresa, maior é a utilização de medidas não financeiras.

Os resultados expostos na Tabela 4 são contrários aos encontrados por Widener (2006), que constatou em seu estudo influência estatisticamente negativa na INTERAÇÃO. Ou seja, a utilização de medidas de recursos humanos no pagamento de bônus das empresas dependentes de capital humano é maior quando elas usam estruturas de remuneração hierárquica. Widener (2006) não encontrou significância com o indicador de crescimento (CRESCER), distinguindo-se dos resultados encontrados nesse estudo.

$\mathrm{Na}$ Tabela 5 apresenta-se o resultado da regressão logística multinominal do Grupo B.

$\mathrm{Na}$ Tabela 5 corrobora-se que o teste qui-quadrado do indicador INTERAÇÃO, de 
4,020 e p $<0,10$, é significativo. Assim, rejeita-se a hipótese nula de que os coeficientes são respectivamente iguais a zero. Como o coeficiente de interação foi positivo, rejeita-se a hipótese $\mathrm{H}_{2}$, uma vez que, o coeficiente indica que a probabilidade da utilização de medidas de recursos humanos no pagamento de bônus das empresas dependentes de capital humano é maior quando usam estruturas de remuneração igualitária.

Tabela 5 - Regressão logística multinominal do Grupo B

\begin{tabular}{c|c|c|c|c}
\hline Efeito Omitido & Coeficientes & $\mathbf{- 2 *} \mathbf{L N}(\mathbf{P})$ do MR & Qui-Quadrado & Significativo \\
\hline CONSTANTE & 0,302 & 115,205 & 0,784 & Não \\
TAMANHO & 0,000 & 116,116 & 1,695 & Não \\
JURÍDICA & $-26,517$ & 117,034 & 2,613 & Não \\
HCAP & $-0,049$ & 115,928 & 1,507 & Não \\
INTERAÇÃO & 0,913 & 118,441 & 4,020 & Sim \\
CRESCER & 0,131 & 121,900 & 7,479 & Sim \\
\hline
\end{tabular}

Significativa em $\mathrm{p}<0,10$.

Fonte: Dados da pesquisa.

O capital humano (HCAP) não teve significância, assim aceita-se a hipótese nula de que os coeficientes são simultaneamente iguais a zero. Os resultados obtidos, por sua vez, demonstram que o indicador CRESCER está significantemente relacionado com o pagamento de bônus aos executivos, em empresas que utilizam especificamente medidas de recursos humanos e dependentes de capital humano.

Widener (2006) obteve resultados diferentes deste estudo, ao observar que a utilização de medidas de recursos humanos no pagamento de bônus das empresas dependentes de capital humano é maior quando usam estruturas de remuneração hierárquica e não igualitária, além de não encontrar influência significativa para a variável CRESCER.

Na Tabela 6 mostra-se o resultado da regressão logística binaria do Grupo C.

Tabela 6 - Regressão logística binaria do Grupo C

\begin{tabular}{c|c|c|c|c}
\hline Efeito Omitido & Coeficientes & $\mathbf{- 2 *} \mathbf{L N}(\mathbf{P})$ do MR & Qui-Quadrado & Significativo \\
\hline CONSTANTE & 0,043 & 48,330 & 0,002 & Não \\
TAMANHO & 0,000 & 50,346 & 2,017 & Não \\
JURÍDICA & $-24,749$ & 50,362 & 2,033 & Não \\
HCAP & $-0,089$ & 51,139 & 2,810 & Sim \\
INTERAÇÃO & 1,302 & 53,007 & 4,679 & Sim \\
CRESCER & 0,358 & 54,630 & 6,301 & Sim \\
\hline
\end{tabular}

Significativa em $p<0,10$.

Fonte: Dados da pesquisa.

Os dados da Tabela 6 demonstram que o teste qui-quadrado do indicador capital humano (HCAP), de 2,810 e p $<0,10$, é significativo. Portanto, rejeita-se a hipótese nula de que os coeficientes são respectivamente iguais a zero. Todavia, o coeficiente do HCAP foi negativo, não fornecendo evidências para confirmar a hipótese $\mathrm{H}_{1 \mathrm{~b}}$, uma vez que o coeficiente indica que a probabilidade de utilização de medidas de recursos humanos no pagamento de bônus diminui com a dependência de capital humano.

$\mathrm{O}$ teste qui-quadrado do indicador de INTERAÇÃO, de 4,679 e p<0,10, é significativo. Como seu coeficiente foi positivo, não se encontram evidências para aceitar a hipótese $\mathrm{H}_{2 \mathrm{~b}}$, pois o coeficiente indica que a probabilidade da utilização de medidas de

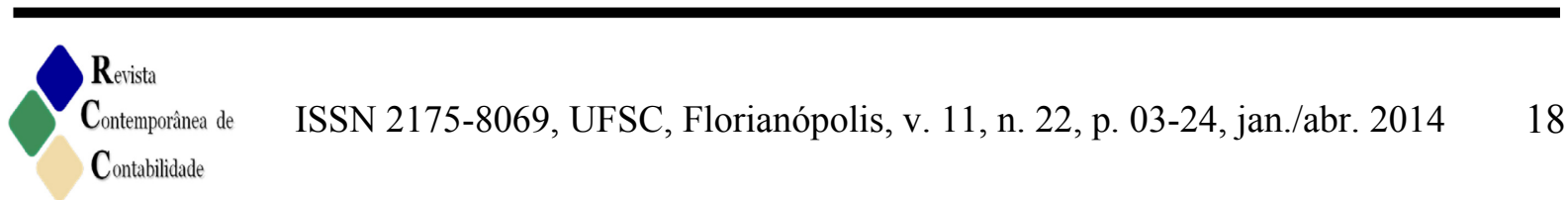


recursos humanos no pagamento de bônus nas empresas dependentes de capital humano é maior quando usam estruturas de remuneração igualitária. A oportunidade de crescimento também está significativamente associada com a utilização de medidas de recursos humanos no pagamento de bônus em empresas dependentes de capital humano.

Na Tabela 7 demonstra-se um comparativo dos resultados deste estudo com a pesquisa de Widener (2006).

Tabela 7 - Comparativo dos resultados desta pesquisa com o estudo de Widener (2006)

\begin{tabular}{c|c|c|c|c|c}
\hline & Variáveis & HCAP & JURÍDICA & TAMANHO & CRESCER \\
\hline \multirow{3}{*}{$\begin{array}{c}\text { Resultados desta } \\
\text { pesquisa }\end{array}$} & FOURCAT & 0,1017 & 0,1411 & 0,1205 & $+0,3062^{* *}$ \\
\cline { 2 - 6 } & HCAP & & $+0,6184^{*}$ & 0,0268 & $-0,0903$ \\
\cline { 2 - 5 } & JURÍDICA & & & $-0,1325$ & $-0,0708$ \\
\cline { 2 - 6 } & TAMANHO & & & & $-0,0196$ \\
\hline \multirow{2}{*}{$\begin{array}{c}\text { Resultados do } \\
\text { estudo de } \\
\text { Widener (2006) }\end{array}$} & FOURCAT & $+0,1342^{*}$ & $-0,0263$ & $+0,3844^{* * *}$ & -0.0461 \\
\cline { 2 - 6 } & HCAP & & $+0,2031^{* * *}$ & $+0,2171^{* * *}$ & $-0,0194$ \\
\cline { 2 - 6 } & JURÍDICA & & & $-0,3292^{* * *}$ & $-0,2701^{* * *}$ \\
\cline { 2 - 6 } & TAMANHO & & & & $+0,0245$ \\
\hline
\end{tabular}

* signif. a $1 \% ; *$; signif. a $5 \% ; * * *$ signif. a $10 \%$.

Fonte: Dados desta pesquisa e do estudo de Widener (2006).

Os resultados deste estudo, confrontados com os de Widener (2006), apresentam diferenças, conforme demonstrado na Tabela 7. A correlação de Pearson do estudo de Widener (2006) aponta que a dependência de capital humano é significativamente correlacionada com tamanho da empresa e estrutura de remuneração. A estrutura de remuneração também está correlacionada com tamanho e oportunidade de crescimento das empresas. Ainda, a variável indicadores para o pagamento de bônus em ações (FOURCAT) está positivamente correlacionada com dependência de capital humano e tamanho da empresa.

No presente estudo, vários resultados foram diferentes do estudo de referência. $\mathrm{O}$ FOURCAT mostrou-se apenas positivamente correlacionado com crescimento da empresa. No entanto, corrobora com a pesquisa do autor ao identificar correlação positiva entre dependência de capital humano e estrutura de remuneração das empresas.

As hipóteses $\mathrm{H}_{1}$ sustentadas por Widener (2006) não foram confirmadas no presente estudo, de que a probabilidade de uso de informações não financeiras no pagamento de bônus aumenta com dependência de capital humano $\left(\mathrm{H}_{1 \mathrm{a}}\right)$; e a probabilidade de uso de medidas de recursos humanos no pagamento de bônus aumenta com dependência de capital humano $\left(\mathrm{H}_{1 b}\right)$. Ambas não foram confirmadas neste estudo, já que não se encontrou relação significativa do HCAP com o FOURCAT quando relacionados ao Grupo A e B. Entretanto, no Grupo C obteve-se significância, porém negativa, assim não se aceitou a hipótese $\mathrm{H}_{1 \mathrm{~b}}$.

No que concerne às hipóteses $\mathrm{H}_{2}$ confirmadas por Widener (2006), não se encontrou alinhamento no presente estudo, já que a interação de HCAP e JURIDICA com FOURCAT foi positivamente significativa. Assim não se confirmaram as hipóteses que prevêem que a probabilidade de uso de medidas não financeiras ou o uso de medidas de recursos humanos no pagamento de bônus aos executivos nas empresas dependentes de capital humano é maior quando se utilizam de estrutura de remuneração hierárquica.

De modo geral, depreende-se que os achados da pesquisa realizada no Brasil diferem dos resultados do estudo de Widener (2006) realizado nos Estados Unidos. Uma das possíveis razões pode decorrer de diferenças na cultura das empresas brasileiras no que tange ao 
pagamento de bônus baseado em ações, que ainda é algo recente. O marco regulatório desta prática no mercado brasileiro ocorreu apenas em 2008, quando o Comitê de Pronunciamentos Contábeis (CPC) aprovou o Pronunciamento Técnico CPC 10 - Pagamento baseado em ações (DIAS, 2010). Nos Estados Unidos esta prática já vem acontecendo, conforme Machado (2012, p. 65), "desde 1938, por meio do Ato Executivo no 34-1823, de 11 de agosto de 1938, da United States Securities and Exchange Commission (SEC)".

\section{Conclusões}

Este estudo objetivou verificar a associação das medidas de desempenho utilizadas no pagamento de bônus aos executivos com a dependência de capital humano e o efeito moderador da estrutura de remuneração em empresas listadas na BM\&FBovespa. Assim, inicialmente descreveu-se a relação entre medidas financeiras e não financeiras (CRESCER, TAMANHO, JURÍDICA, HCAP, INTERAÇÃO) com o pagamento de bônus aos executivos. Na seqüência, utilizou-se estatística descritiva, com o intuito de caracterizar os dados da pesquisa. Em seguida aplicou-se nas variáveis a correlação de Pearson. E, por fim, utilizou-se a regressão logística para comprovar as hipóteses da pesquisa. A pesquisa consubstanciou-se de um estudo empírico com análise documental de 60 empresas da BM\&FBovespa.

O presente estudo foi inspirado na pesquisa de Widener (2006) realizada em empresas dos Estados Unidos, vislumbrando-se condições de reaplicação da pesquisa no cenário brasileiro. Os testes estatísticos realizados com dados de 2011 de companhias abertas listadas na BM\&FBovespa, apontaram uma relação negativa significante entre capital humano e uso de medidas de recursos humanos para pagamento de bônus aos executivos. No que concerne à interação do capital humano e a estrutura de remuneração da empresa, os resultados demonstraram relação positiva significante de medidas não financeiras e de recursos humanos com pagamento de bônus aos executivos. Esses achados não coadunam com as hipóteses propostas por Widener (2006). Os testes não apontaram existência de correlação, nem positiva e nem negativa, entre o HCAP e o FOURCAT.

Para as hipóteses formuladas e confirmadas na pesquisa de Widener (2006), os resultados não foram conclusivos neste estudo. Não foram encontradas evidências para confirmar a hipótese $\mathrm{H}_{1 \mathrm{a}}$, de que a probabilidade do uso de informações não financeiras no pagamento de bônus aumenta com a dependência de capital humano. $\mathrm{O}$ mesmo ocorreu com o teste da hipótese $\mathrm{H}_{1 b}$, que a probabilidade do uso de medidas de recursos humanos no pagamento de bônus aumenta com a dependência de capital humano. Também não se confirmou a hipótese $\mathrm{H}_{2 \mathrm{a}}$, de que a estrutura de remuneração modera a relação entre a utilização de medidas não financeiras e a dependência de capital humano. Da mesma forma não se confirmou a hipótese $\mathrm{H}_{2 \mathrm{~b}}$, que a estrutura de remuneração modera a relação entre a utilização de medidas de recursos humanos e a dependência de capital humano.

Fazendo-se um comparativo dos resultados de ambas as pesquisas, destaca-se que Widener (2006) constatou que os gastos com capital humano estão positivamente relacionados com o pagamento de bônus em ações aos executivos; já a interação do capital humano com a estrutura de remuneração está negativamente relacionada com a variável interação entre a variável jurídica e o capital humano. Na pesquisa realizada em empresas brasileiras, as evidencias mostraram-se diferentes das encontradas em empresas estadunidenses, conforme a pesquisa de Widener (2006) naquele país, quanto ao tipo de

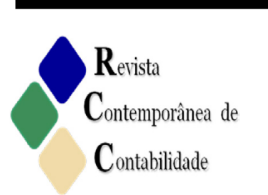


remuneração (igualitária ou hierárquica) que é realizado na empresa.

Os resultados apontados neste estudo diferem do estudo de Widener (2006), revelando diferenças entre as empresas brasileiras e as estadunidenses. Uma explicação plausível para as diferenças encontradas pode decorrer do fato da prática de remuneração variável a partir do pagamento de bônus, baseado em ações, ser recente no Brasil, cujo marco regulatório ocorreu em 2009. Ao contrário dos Estados Unidos, em que esta prática já ocorre nas empresas desde o ano de 1938, conforme Machado (2012). Outra explicação para as diferenças pode estar relacionada ao tipo de acionista majoritário das empresas, se privado, agência de governo ou estatal, conforme observado no estudo de Firth, Peter e Oliver (2006) em empresas chinesas.

Assim, conclui-se que o uso de medidas de desempenho se relaciona com o pagamento de bônus aos executivos nas empresas pesquisadas. De modo geral, constatou-se que o uso de medidas de recursos humanos para pagamento de bônus diminui com a dependência de capital humano. Observou-se que a probabilidade de uso de medidas não financeiras e de recursos humanos no pagamento de bônus aos executivos nas empresas dependentes de capital humano é maior quando as empresas utilizam estruturas de remuneração igualitária, ao contrário da pesquisa de Widener (2006), em que isso ocorreu com estruturas de remuneração hierárquica.

As limitações desta pesquisa se centralizam nos recortes efetuados para a elaboração do estudo, bem como pela utilização de uma metodologia idêntica ao estudo de Widener (2006). Assim os resultados desta pesquisa não podem ser generalizados, se restringem a amostra analisada. Recomenda-se para futuras pesquisas ampliar o número de empresas, selecionando inclusive aquelas que não negociam ações na BM\&FBovespa. Sugere-se também utilizar outros períodos de tempo e fatores não considerados neste estudo.

\section{Referências}

ANDERSON, D.R.; SWEENEY, D.J.; WILLIAMS, T.A. Estatística aplicada à administração e economia. São Paulo: Thomson Learning, 2002.

BALKCOM, J.E.; ITTNER, C.D.; LARCKER, C.D. Strategic performance measurement: lessons learned and future directions. Journal of Strategic Performance Measurement, v. 1, n.2, p. 22-32, Apr./May 1997.

BALKIN, D.B.; GOMEZ-MEJIA, L.R. Matching compensation and organization strategies. Strategic Management Journal, v. 11, n. 2, p 153-169, Feb. 1990.

BALKIN, D.; MARKMAN, G.; GOMEZ-MEJIA, L. Is CEO pay in high technology firms related to innovation? The Academy of Management Journal, v. 43, n. 6, p. 1118-1129, Dec. 2000.

BALSAM, S.; FAN, H.; MAWANI, A. Reaching for the stars and stripes: how Canadian CEO compensation is approaching U.S. levels. Working Paper, 2011.

BALSAM, S.; FERNANDO, G.D.; TRIPATHY, A. The impact of firm strategy on performance measures used in executive compensation. Journal of Business Research, v. 64, n. 2, p. 187-193, Feb. 2011. 
BANKER, R.D.; LEE, S.Y; POTTER, G. A field study of the impact of a performance-based incentive plan. Journal of Accounting \& Economics, v. 21, n. 2, p. 195-226, Apr. 1996.

BUSHMAN, R.; INDJEJIKIAN, R.; SMITH, A. CEO compensation: the role of individual performance evaluation. Journal of Accounting and Economics, v. 21, n. 2, p. 161-193, Apr. 1996.

COMISSÃO DE VALORES MOBILIÁRIOS (CVM). Instrução CVM no 480, de 7 de dezembro de 2009. Disponível em: <http://www.cvm.gov.br/>. Acesso em: 07 dez. 2013.

COWHERD, D.M.; LEVINE, D.I. Product quality and pay equity between lower-level employees and top management: an investigation of distributive justice theory.

Administrative Science Quarterly, v. 37, n. 2, p. 302-320, Jun. 1992.

CRAWFORD, R. Na era do capital humano. São Paulo: Atlas, 1994.

DALMACIO, F.Z.; REZENDE A.J.; SLOMSKI, V. Análise setorial das medidas de performance utilizadas nos contratos de remuneração dos gestores. Revista Universo Contábil, v. 5, n. 3, p. 06-23, jul./set. 2009.

DIAS, W.O. Remuneração variável nas empresas brasileiras: estudo de determinantes da utilização de stock options. 2010. 105f. Dissertação (Mestrado em Ciências Contábeis) Universidade Federal de Minas Gerais, Belo Horizonte, 2010.

EDVINSSON, L.; MALONE, M.S. Capital intelectual. São Paulo: Makron, 1998.

FÁVERO, L.P.; PATRÍCIA, B.; SILVA, F.L.; CHAN, B.L. Análise de dados: modelagem multivariada para tomada de decisões. Rio de Janeiro: Elsevier, Campus, 2009.

FIRTH, M.; PETER, M. Y. F.; OLIVER, M. R. Corporate performance and CEO compensation in China. Journal of Corporate Finance, v. 12, n. 4, p. 693-714, 2006.

GERHART, B.; MINKOFF, H.B.; OLSEN, R.N. Employee compensation: theory, practice, and evidence. In: FERRIS, G.R.P.; ROSEN, S.D.; BARNUM, D.T. (Eds.). Handbook of human resources management. Cambridge, MA: Blackwell, 1995. pp. 528-547.

GRANT, R.M. The resource-based theory of competitive advantage: implications for strategic formulation. California Management Review, v. 33, n. 3, p.114-135, Mar. 1991.

HAJIHA, Z.; HASANLOO, S. An empirical study of the relationships among human capital value and profitability and market value: comparison of knowledge-based industries and non knowledge-based industries. Asian Journal of Business and Management Sciences, v. 1, n. 3, p. 105-114. 2012.

HOSMER, D.W.; LEMESHOW, S. Applied logistic regression. New York: John Wiley, 1989.

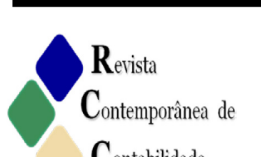


HSU, L.C.; WANG, C.H. Clarifying the effect of intellectual capital on performance: the mediating role of dynamic capability. British Journal of Management, v. 23, n. 2, p. 179205, Jun. 2012.

ITTNER, C.D.; LARCKER, D.F.; RAJAN, M.V. The choice of performance measures in annual bonus contracts. The Accounting Review, v. 72, n. 2, p. 231-255, Apr. 1997.

KAPLAN, R.S.; NORTON, D.P. A estratégia em ação: balanced scorecard. 2. ed. Rio de Janeiro: Campus, 1997.

KAPLAN, R.S.; NORTON, D.P. The balanced scorecard: measures that drive performance. Harvard Business Review, v. 70, n. 1, p. 71-79, Jan./Feb.1992.

KRAUTER, E. Contribuições do sistema de remuneração dos executivos para o desempenho financeiro: um estudo com empresas industriais brasileiras. 2009. 180f. Tese (Doutorado em Administração) - Universidade de São Paulo, São Paulo, 2009.

LARRATE, M.A.; OLIVEIRA, F.N.; CARDOSO, A.S. Governança corporativa, remuneração dos gestores e produtividade da firma. Revista do BNDES, n. 36, p. 245-272, 2011.

LAU, C.M. Nonfinancial and financial performance measures: How do they affect employee role clarity and performance? Advances in Accounting, Incorporating Advances in International Accounting, v. 27, n. 2, p. 286-293, Dec. 2011.

LAVERTY, K.J. Economic "short-termism": the debate, the unresolved issues, and the implications for management practice and research. The Academy of Management Review, v. 21, n. 3 , p. $825-860$, jul.1996.

LEV, B. Intangibles: management, measurement, and reporting. Washington: Brookings, 2001.

LIM, L.L.K.; CHAN, C.C.A. DALLIMORE, P. Perceptions of human capital measures: from corporate executives and investors. Journal of Business and Psychology, v. 25, n. 4, p. 673$688,2010$.

MACHADO, D. G. Influência da política de remuneração dos executivos no nível de gerenciamento de resultados em empresas industriais brasileiras, estadunidenses e inglesas. 2012. 273f. Tese (Doutorado em Ciências Contábeis e Administração) Universidade Regional de Blumenau, Blumenau, 2012.

MCKENZIE, F.C.; SHILLING, M.D. Avoiding performance measurement traps: ensuring effective incentive designs and implementation. Compensation and Benefits Review, v. 30, n. 4, p. 57-65, Jul./Aug. 1998.

MONTEMAYOR, E. Congruence between pay policy and competitive strategy in high- 
performing firms. Journal of Management, v. 22, n. 6, p. 889-908, 1996.

OYADOMARI, J.C.T.; CESAR, A.M.R.V.C.; SOUZA, E.F.; OLIVEIRA, M.A. Influências da remuneração de executivos na congruência de metas. Revista Contemporânea de Contabilidade, v. 1, n. 12, p. 53-74, jan./jun. 2009.

SCHULTZ, T.W. Investment in human capital. The American Economic Review, v. 51, n. 1, p. 1-17, Mar. 1961.

SCHULZ, M. The uncertain relevance of newness: organizational learning and knowledge flows. Academyof Management Journal, v. 44, n. 4, p. 661-681, Aug. 2001.

STEWART, T.A. Capital Intelectual: a nova vantagem competitiva das empresas. Rio de Janeiro: Campus, 1998.

WANG, I; SHIEH, C.J. Effect of human capital investment on organizational performance. Social Behavior and Personality: An International Journal, v. 36, n. 8, p. 1011-1022, 2008.

WIDENER, S.K. Human capital, pay structure, and the use of performance measures in bonus compensation. Management Accounting Research, v. 17, n. 2, p. 198-221, 2006.

XAVIER, P.R; SILVA, M.O.; NAKAHARA, J.M. Remuneração variável: quando os resultados falam mais alto. São Paulo: Makron Books, 1999. 